\title{
Super Profile analysis of socioeconomic variations in coronary investigation and revascularisation
}

\section{rates}

\author{
C J Manson-Siddle, M B Robinson
}

South Humber Health Authority

C J Manson-Siddle

Nuffield Institute for Leeds

M B Robinson

Correspondence to: C J Manson-Siddle, South Humber Health Authority, Health Place, Wrawby Road, Brigg, North Lincolnshire DN20 8GS.

Accepted for publication Health, University of 2 December 1997

\begin{abstract}
Objectives-To investigate socioeconomic variations in the utilisation of tertiary cardiology services.

Design-Cross sectional ecological study, using the Super Profile classification of enumeration districts, and ischaemic heart disease standardised mortality ratios as a proxy for need.

Setting-The former Yorkshire Regional Health Authority area in England and its seven constituent district health authority areas.

Subjects-Patients with a primary diagnosis of ischaemic heart disease aged $\geqslant 25$ years who underwent investigation by angiography, or treatment by coronary artery bypass grafting (CABG) or percutaneous transluminal coronary angioplasty (PTCA), as a primary procedure between April 1992 and March 1994 in an NHS hospital.

Main results-There is an overall increasing trend in investigation and revascularisation rates from the affluent to the deprived in the region suggesting equity. However, the gradient is slight compared with the corresponding mortality gradient. Age specific analysis shows a more appropriate trend in rates for the under 65s, but a downward trend from affluence to deprivation for the elderly. Much of the regional trend is caused by very high rates in one geographically small but densely populated district that has two tertiary
\end{abstract}

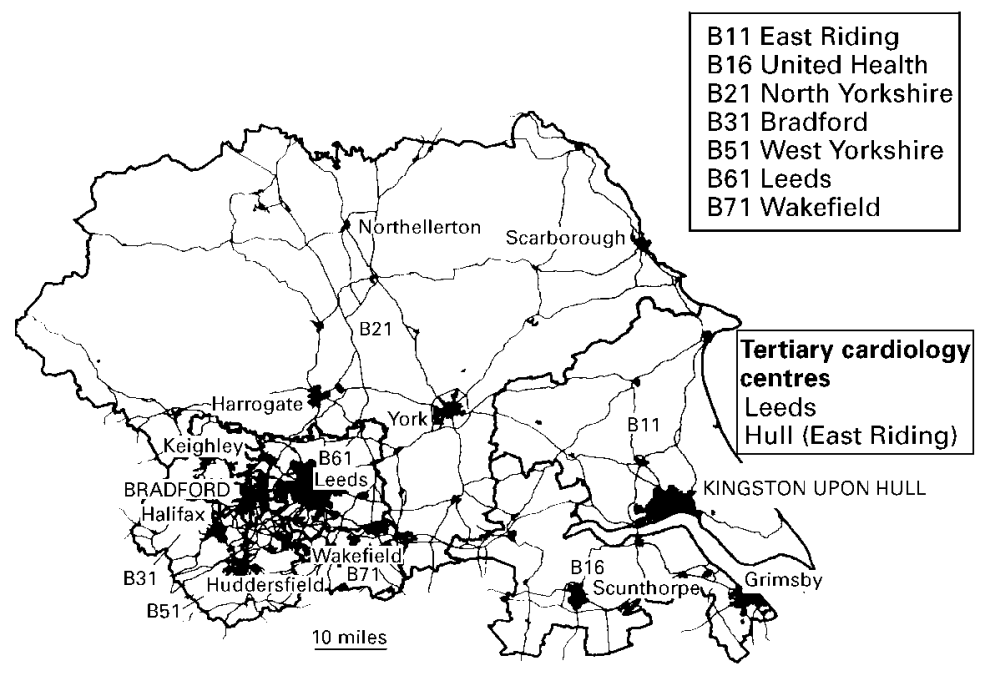

Figure 1 Yorkshire Regional Health Authority. cardiology centres. In other districts, with higher heart disease mortality but much lower procedure rates, there is a decreasing trend from the affluent to the deprived suggesting considerable inequity.

Conclusions-This study confirms wide socioeconomic variations in coronary investigation and revascularisation within the former Yorkshire Region, suggesting that in some districts need is not being met and that service utilisation is inequitable. Such inequities are over and above those that result from proximity to tertiary cardiology centres.

(F Epidemiol Community Health 1998;52:507-512)

Geographical inequalities in coronary heart disease mortality and morbidity have been reported at national, regional, district, and electoral ward levels, and shown to be associated with socioeconomic status. ${ }^{1-3}$ While there has been an overall decline in mortality in recent years, evidence suggests it is at the expense of widening inequalities. ${ }^{4}$ The need for action to tackle variations in health has been acknowledged $^{5}$ as a central determinant to the achievement of the Health of the Nation ${ }^{6}$ strategy. Although the main determinants of health are individual lifestyle factors and general socioeconomic, cultural, and environmental factors, inequities in health care access and utilisation can also influence cure or survival ${ }^{7}$ and thus require monitoring and resolving.

Equity in health care, one of the founding principles of the NHS, means fair distribution across individuals and groups in society according to need. Equal access to health care for equal need should account for the differential costs to patients (supply factors), and equal utilisation for equal need should also consider demand factors and ensure that there are additional resources in place to overcome the extra barriers faced by the most deprived. ${ }^{8}$ Inequalities in hospital utilisation rates have previously been demonstrated, and again associated with socioeconomic status. ${ }^{239}$ In highlighting the issue of equity the Audit Commission ${ }^{10}$ specifically advocates the monitoring of patterns of revascularisation provision. This study explores the hypothesis that the socioeconomically deprived, with more heart disease mortality and morbidity, do not receive more investigations (coronary angiography) or revascularisations - that is, service utilisation is inequitable and the needs of the socioeconomically deprived are not being met. 
I Affluent achievers-mainly middle-aged professional couples with children at university, living in their own large detached homes

II Country life-mainly young/middle-aged adults living in detached homes, often working there eg farmers, and often owning a second home

III Thriving greys-mainly older middle-aged professionals or managers, semi or detached home owners whose children have left home

IV Settled suburbans-many older couples with children living in semidetached houses and having white collar occupations, with part-time working housewives

$\mathrm{V}$ Nest builders-young, often double-income, white collar or skilled manual families living in mortgaged semi-detached or terrace homes including military families

VI Producers-usually older, blue collar, owner occupiers of semis or living in council houses

VII Senior citizens-older, retired couples or single old ladies living alone, or young single transients living in seaside towns, both groups buying terraces or flats

VIII Urban venturers-high proportion of ethnic minorities, also members of armed forces, high income young professionals renting in London, many non-car owners

IX Hard-pressed families-high numbers of young people and single parents living in council terraces, often unemployed and non-car owners

$X$ Have-nots-many single-parent families and few married couples, living in crowded, rented council or housing association accommodation, often unemployed and non-car owners

Figure 2 Super Profile lifestyle groups.

Evidence of the effectiveness of revascularisation has been available for some time. ${ }^{11}{ }^{12}$ Despite this, wide variations in the utilisation of revascularisation have been demonstrated between countries, regions, and districts. ${ }^{13}{ }^{14}$ While these differences have been shown to be related to the availability and proximity of cardiologists and catheterisation laboratories, ${ }^{15}$ the association with deprivation is less clear. A recent study ${ }^{3}$ in one health authority district found no relation at all between revascularisation and deprivation using Townsend scores and electoral wards. However, a national aggregation of electoral wards into quartiles of Townsend deprivation score, suggested inequitable provision of coro-

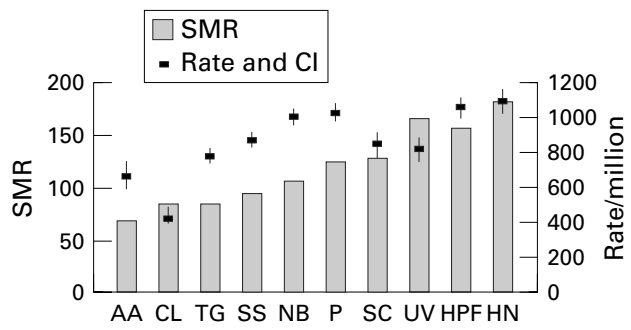

Figure 3 Yorkshire Region under 65s SMRs and age/sex standardised $C A B G / P T C A$ rates. Source for SMRs: Yorkshire Health Public Health Report $1994 .^{32}$

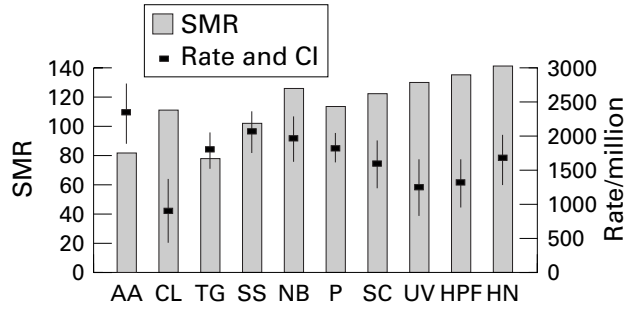

Figure 4 Yorkshire Region $65-74$ years SMRs and age/sex standardised CABG/PTCA rates. Source for SMRs: Yorkshire Health Public Health Report $1994 .^{32}$ nary artery bypass grafting (CABG) for men but not women. ${ }^{16}$ Kee et $a l^{17}$ failed to detect any socioeconomic differences in investigation rates in Northern Ireland using similar methods. Using SCOTDEP scores based on postal code, Findlay $e t ~ a l^{18}$ showed an excess of investigation of patients from low socially deprived areas. More than fivefold geographical differences in district rates for CABG and for percutaneous transluminal coronary angioplasty (PTCA) have been shown in the UK, ${ }^{19}$ largely because of differences in supply and geographical proximity; with higher intervention rates associated with more deprived districts, but conflictingly also associated with lower standardised mortality ratios (SMRs). ${ }^{15}$

The contradictory results shown by different studies may partly be caused by methodological differences. Because socioeconomic data are not routinely available for individuals undergoing tertiary cardiac surgery, ecological studies linking area-based census information to individual health information are necessary. In addition to the potential problems associated with the ecological fallacy, the size of geographical areas chosen for comparison, plus the choice of census variables to indicate deprivation and the methods of combination may affect the results.

Previous local analysis, ${ }^{2}$ using electoral wards as the geographical area of analysis and Jarman underprivileged area score (UPA) as a measure of relative deprivation in one district of the former Yorkshire Region (United Health, Grimsby and Scunthorpe, see figure 1), showed a strong positive association between mortality and deprivation, but a much weaker correlation between heart disease procedures and mortality. In an attempt to overcome some of the problems that may be responsible for the conflicting results previously shown, this paper uses the relatively novel Super Profile ${ }^{20}$ methodology.

\section{Method}

1991 Census small area statistics for the former Yorkshire Region provided the population denominator. These data for each enumeration district (in five year age bands by sex to facilitate direct standardisation) were electronically assigned to one of 10 Super Profile Lifestyle groups, figure 2. Summation using Excel software provided district and regional population totals by sex and age band for each lifestyle group.

Regionally collated hospital activity data were acquired for residents of the Yorkshire Region who underwent (at any NHS unit either within or outside the region) an OPCS " $\mathrm{K}$ " code procedure, or whose primary diagnosis was recorded as ischaemic heart disease (ICD9 410-414) or chest pain (ICD9 786.5) during the financial years 1992/3 (27368 FCEs) and 1993/4 (33675 FCEs). Two years data were used to increase the study size. Some $98.3 \%$ and $98.9 \%$ respectively of FCEs in these data files were successfully matched to a lifestyle group using postcodes. Merging the files and restricting to one episode per patient aged 25 years and over with a primary 
Table 1 SMRs and average annual (1992-94) age-sex standardised investigation and revascularisation rates/million with $95 \%$ confidence limits

\begin{tabular}{|c|c|c|c|c|}
\hline Geographical area & $\begin{array}{l}C H D \\
S M R^{\star}\end{array}$ & District rates & Affluent achievers(I) rates & Have-nots $(X)$ rates \\
\hline \multicolumn{5}{|l|}{$C A B G / P T C A$ rates } \\
\hline \multicolumn{5}{|l|}{ Yorkshire Region: } \\
\hline 25 years and over & & & $812(723,921)$ & $1112(998,1227)$ \\
\hline $25-64$ years & & & $662(574,751)$ & $1098(1022,1175)$ \\
\hline $65-74$ years & & & $2331(1883,2780)$ & $1660(1299,2021)$ \\
\hline \multicolumn{5}{|c|}{ District 25 years and over: } \\
\hline Leeds & 100 & $1587(1501,1673)$ & $1001(785,1217)$ & $1869(1577,2161)$ \\
\hline United Health & 119 & $690(612,768)$ & $1006(671,1340)$ & $659(399,920)$ \\
\hline West Yorkshire & 121 & $796(727,866)$ & $1023(748,1298)$ & $641(386,895)$ \\
\hline Bradford & 113 & $804(725,833)$ & $567(343,792)$ & $1002(711,1294)$ \\
\hline Wakefield & 121 & $1056(952,1160)$ & $721(366,1077)$ & $1252(821,1684)$ \\
\hline North Yorkshire & 103 & $662(608,715)$ & $642(492,793)$ & $784(394,1175)$ \\
\hline East Riding & 106 & $885(811,959)$ & $759(523,995)$ & $854(639,1069)$ \\
\hline \multicolumn{5}{|l|}{ Angiography rates } \\
\hline \multicolumn{5}{|l|}{ Yorkshire Region: } \\
\hline 25 years and over & & & $1216(1107,1325)$ & $2031(1875,2186)$ \\
\hline $25-64$ years & & & $1035(924,1147)$ & $2049(1872,2225)$ \\
\hline $65-74$ years & & & $2936(2433,3440)$ & $2783(2315,3250)$ \\
\hline \multicolumn{5}{|c|}{ District 25 years and over: } \\
\hline Leeds & 100 & $2643(2532,2754)$ & $1755(1470,2040)$ & $3323(2929,3717)$ \\
\hline United Health & 119 & $1272(1166,1377)$ & $1489(1082,1985)$ & $1205(851,1558)$ \\
\hline West Yorkshire & 121 & $1296(1208,1384)$ & $1137(849,1424)$ & $1533(1146,1920)$ \\
\hline Bradford & 113 & $960(874,1046)$ & $716(462,970)$ & $1168(855,1481)$ \\
\hline Wakefield & 121 & $1902(1798,2007)$ & $1302(818,1786)$ & $2063(1521,2605)$ \\
\hline North Yorkshire & 103 & $1043(975,1110)$ & $885(705,1064)$ & $1677(1111,2243)$ \\
\hline East Riding & 106 & $1613(1513,1713)$ & $1328(1018,1639)$ & $1862(1544,2180)$ \\
\hline
\end{tabular}

*Source: Department of Health. Public Health Common Data Set 1993.

diagnosis of CHD (ICD9, 410-414) and a primary operation code of either CABG (OPCS$4 \mathrm{R}, \mathrm{K} 40-46)$ or PTCA (K49-50), yielded a final revascularisation database for analysis of 4232 patients (985 women and 3247 men). This process repeated for angiography (K6365) resulted in a database of 6981 patients (5266 men and 1715 women). Thus investigative procedures and revascularisations were not subsidiary to any other procedure (for example, valvular) nor the result of congenital defects. One episode per patient was included assuming that once having gained access to the service any barriers had been overcome.

Average annual age adjusted utilisation rates per million population with $95 \%$ confidence limits were calculated for the region and its seven constituent districts, and then compared to assess equity of utilisation. Rates were standardised to the European Standard Population. ${ }^{6}$ Detailed examination of utilisation rates across lifestyle groups for each district, and for each lifestyle group across districts is reported elsewhere. ${ }^{21}$ SMRs for districts and for lifestyle groups are used as a proxy for need.

\section{Results}

There is an overall increase in the under 65 years regional revascularisation rate across the lifestyle groups from Affluent achievers (I) to

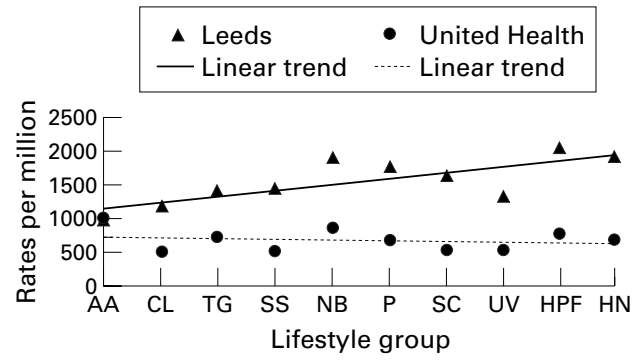

Figure 5 Leeds and United Health average annual (1992-4) age/sex standardised CABG/PTCA rates.
Have-nots (X), figure 3. However, the gradient is not as steep as expected given that those in the poorest groups are twice as likely to die from heart disease as those in the affluent groups.

The older age group experiences a decrease in revascularisation rates from the affluent to the deprived despite increasing mortality experience, and suggesting considerable inequity, figure 4.

These trends are not consistent across all Lifestyle Groups, there being a considerably lower rate for the country life (II) profile, repeated in all regional age group and sex analyses and in the angiography utilisation analysis. $^{21}$

Comparing districts, there is an almost threefold difference in both investigation and revascularisation rates, table 1 . Despite having a national average coronary heart disease mortality experience (and possibly contributing to this) residents of Leeds district have the highest investigation and revascularisation rates and a socioeconomically equitable service, figure 5 . This district's rates profoundly influence the regional results. Residents of United Health (Grimsby and Scunthorpe district), which has

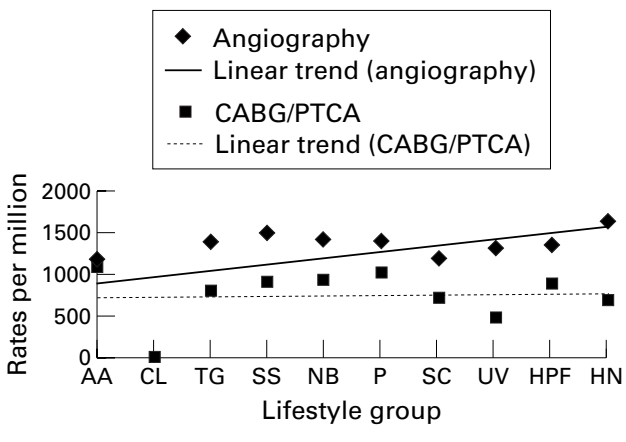

Figure 6 Average annual (1992-4) age/sex standardised angiography and CABG/PTCA rates compared for West Yorkshire. 
one of the highest SMRs of the seven districts in the former Yorkshire Region, table 1, not only experience low investigation and revascularisation rates but also a downward trend from Affluent achievers (I) to Have-nots (X), suggesting considerable inequalities in health care utilisation, figure 5. Residents of West Yorkshire, again experiencing high mortality fare worse, showing a difference between the trend for angiography and that for revascularisation, figure 6 .

Affluent achievers (I) are likely to gain access to tertiary cardiology services regardless of district of residence.

\section{Discussion}

Using Super Profile multidimensional classification we have demonstrated that there are wide socioeconomic inequities in angiography and revascularisation within the former Yorkshire Region, particularly marked in some districts where rates are low but mortality experience high, and particularly in the older age group where death rates are also considerably higher. On the whole, low rates are experienced by the Rural affluent (country life II), whereas the Affluent achiever (I) group seem to obtain surgical interventions regardless of geographical residence, and despite lesser need as measured by mortality. Possible explanations for the variations shown here are discussed.

\section{METHODOLOGICAL LIMITATIONS}

Hospital episode statistics (HES) can readily be used to explore variations in service utilisation by age, sex, and geographical location. Variation by ethnic group can also now be assessed. Socioeconomic variation, however, is difficult to determine because the necessary data on individual patient income, expenditure, and wealth to ascertain poverty are not routinely collected, and nor are individual proxy measures such as social class, education, or occupation. To overcome this, patients are often classified (using postcodes) by the overall socioeconomic characteristics of the area in which they live - that is, by a deprivation index derived from census data and thus based on the aggregate characteristics of the majority of individuals resident in the area.

This census-based (ecological) methodology, linking individual health outcomes or eventsthat is, death, hospital episode or operationwith an aggregate indicator of deprivation for exploring socioeconomic associations, is subject to the ecological fallacy ${ }^{22}$ and thus criticised, (the characteristics of an area may not represent the characteristics of an individual). However, Kreiger $^{24}$ in the USA validates the census-based approach by matching census data to individual membership records in a pre-paid health plan. UK evidence using individuals as the unit of observation also supports the notion that ecological correlations between deprivation and health are produced by the associations of the relevant variables in individuals. ${ }^{25}$ Sloggett and $\mathrm{Joshi}^{26}$ use data from the Office of National Statistics Longitudinal Study to show that the association between area disadvantage and prema-

\section{KEY POINTS}

- Inequities in utilisation of health care can influence cure or survival and thus need monitoring and resolving.

- Super Profile analysis shows wide socioeconomic inequities in angiography and revascularisation utilisation between districts and within districts in one region.

- Inequities shown are over and above those associated with proximity to a tertiary cardiology centre.

- Districts with low angiography and/or revascularisation rates should consider increasing their provision, targeted at the socioeconomically disadvantaged.

ture mortality is explained by individual socioeconomic circumstance.

Evidence suggests that the smaller the area the more likely a patient is to reflect its characteristics. ${ }^{24}{ }^{27}$ Hence enumeration district (ED) analysis should be less prone to the ecological fallacy, although one study comparing EDs and electoral wards ${ }^{28}$ showed no differences. Whereas most previous studies exploring socioeconomic equity of angiography or revascularisation and showing inconclusive results use districts or electoral wards, the Super Profile methodology uses EDs, the smallest and most homogeneous area for which census data are available. Although the impact of the ecological fallacy should therefore be minimised, this can only be tested by collecting detailed information from individual patients and comparing with their Super Profile assigned Lifestyle Group. However, the scope for ecological fallacy is limited because action to resolve specific inequities would be targeted at individuals rather than aimed at the entire population.

Which census variables to choose as indicators of socioeconomic status and how many is uncertain, as is the best method of aggregation to provide a measure of deprivation. Simple addition fails to account for the differential impact of indicators. This may be overcome by weighting, but the theoretical basis for the derivation of weights (dependent on the concept of deprivation being measured) needs careful consideration. Criticism abounds in the use of such indicators other than for the purpose they were derived (for example, Jarman UPA). ${ }^{29}$

Deprivation, however, is a multidimensional concept requiring a multidimensional view of socioeconomic circumstance if socioeconomic diversity is to be more meaningfully reflected. The Super Profile methodology uses multivariate techniques to combine census indicators for EDs. Principal component analysis transforms 120 highly correlated census variables that reflect deprivation to fewer less correlated variables, while maintaining as much of the original variation in the data as possible. Cluster analysis groups similar EDs at three levels. The most aggregated level is used for this 
analysis with the 10 lifestyle groups sequenced using the scores of the first principal component to form an index of affluence, figure 2 .

Super Profile thus uses EDs, the smallest and most homogeneous area for which census data are available, and a multidimensional concept of deprivation while attempting to overcome problems of multi-collinearity. The usefulness of the methodology has been effectively demonstrated for the analysis of health conditions incidence data, ${ }^{30}$ in measuring child health inequalities, ${ }^{31}$ and in assessing socioeconomic differences in Health of the Nation target indicators, for example, coronary heart disease, stroke, breast cancer, lung cancer mortality, etc. ${ }^{32}$

Although Super Profile is a multidimensional classification and arguably more suitable than unidimensional indices, interpretation of the results depends on the system measuring what it purports to measure. Good correlation with other deprivation scores (Townsend, Carstairs) suggests the Super Profile ranking of affluence is consistent. ${ }^{32}$ Furthermore, a review of multidimensional classification systems concludes that there is a place for Super Profiles in health service research. ${ }^{33}$

Other methodological limitations that may cause bias are incomplete and inaccurate data, resulting in failure to assign some postcodes to a lifestyle group. This could be because of postcode inaccuracies in the hospital episode data, or to the lack of completeness of the OPCS postcode to ED directory. However, as only $1.5 \%$ of approximately 61000 FCEs (from which the final 11000 FCEs were extracted) failed to be matched to a Super Profile group, and there is no reason to suspect any systematic bias among these, incomplete or inaccurate data are not thought to be a problem in this study.

Private hospital utilisation for tertiary cardiology over the period may also have affected the results. These data are not routinely available and thus $10-20 \%$ of cardiac surgical interventions may have been excluded. However, as it is the affluent who are more likely through either self funding or insurance to use private hospitals, the inclusion of these data would only decrease the gradient effect from Affluent achievers (I) to Have-nots (X) seen for the region as a whole, and for the comparatively well provided districts. In districts where there is already a downward trend from Affluent achievers (I) to Have-nots (X), the inclusion of private hospitals would probably increase socioeconomic inequalities shown.

DATA ARTEFACT

It is unlikely that systematic bias explains the observed differences because the data are obtained from several tertiary centres treating patients from all seven districts, and all 10 Super Profile groups. Also, comparative rates for different socioeconomic groups are more important than definitive accurate levels of provision, so absolute accuracy of HES data is unimportant for this study.
PATIENT RELATED FACTORS

Although rates have been standardised for age and sex, ethnicity was not routinely collected between 1992-4, prohibiting standardisation for this variable. Ethnic minorities contributed only $1-2 \%$ to the population totals in most districts, for example, United Health, but there were larger ethnic minority populations in West Yorkshire and Bradford. Also, obesity, smoking, and alcohol consumption might be confounding factors, but routine data are not available to assess these at ED level. Contraindications to procedures may be more prevalent in the lower socioeconomic groups and other comorbidities, for example, chronic obstruction of airways disease, may influence clinical appropriateness for revascularisation. Inability to adjust for these factors might have overestimated the degree of inequity but is unlikely to explain all of it.

Attitudes, expectations, and illness behaviour, which may in part explain the results, are beyond the scope of this study. However the Inverse Care Law, ${ }^{34}$ which states that the more affluent although less needy are empowered to gain greater access, may explain higher rates in the Affluent achievers (I) and Thriving greys (III) profile groups.

More research is required to determine reasons for low cardiac surgical interventions in the Country life (II) group. One possible factor is their high rate of self employment. ${ }^{32}$

SERVICE RELATED FACTORS

Geographical proximity to tertiary centres and cardiologists has been previously shown partially to explain differences in CABG/PTCA rates. ${ }^{15}$ This may be responsible for the very high rates in Leeds, a district of comparatively small geographical area but with two providers of tertiary cardiology services (at the time of the study). Low country life (II) profile rates observed may be conversely explained.

Clinical judgement or attitudes towards individual patients may partially explain differences. One study suggests that GP decisions about referral for angiography may contribute to unequal access for some patient groups. ${ }^{35}$ Fundholding status may also influence referrals. Appropriateness of referral has been shown in the United States to explain some variations in the use of cardiac surgical interventions. ${ }^{3637}$ Further research would be required to explore the extent to which such factors may explain the observed differences.

Compared with previously using Jarman and electoral ward-based analysis in one district (United Health), where only a very weak association was found between heart disease procedures and mortality across deprivation groups, Super Profile lifestyle grouping shows a clear association between deprivation and procedures, suggesting an advantage for ED level analysis and multidimensional socioeconomic grouping. However, this comparison would have to be more formally tested using other deprivation indices, for other areas of the country, and for other specialty provision, for example, orthopaedics/total hip replacement, before the use of Super Profiles could be more generally 
recommended. In addition, conclusions in this paper have been based on the visual presentation of trends, and further work exploring the statistical association between lifestyle group rates and SMRs would be valuable. The public health significance of our results could be further clarified using the rates seen in the Affluent achievers (I) group as normative and calculating the shortfall in each of the other lifestyle groups.

If its sensitivity suggested by our studies was confirmed, ease of application would make the Super Pofile classification a useful tool for routinely monitoring access to health care. The process is straight forward. Once census population data are super profiled and spread sheets set up to calculate standardised rates and confidence intervals, monitoring requires only periodic analysis of readily available contract minimum data set (CMDS) data. Monitoring might in itself encourage further improvements in the quality of routine data.

As the Super Profile system electronically assigns a lifestyle group to individual postcodes, action to overcome any socioeconomic inequities found could include, for example, flagging socioeconomic group on health data as for ethnicity (for example, general practice morbidity datasets, hospital case notes, and outpatient/inpatient datasets), followed by prioritisation of the deprived. As correlation between different measures of deprivation has been shown to be particularly consistent at the extremes of the measures, suggesting greater accuracy of ecological methods in predicting the most affluent or most deprived, ${ }^{38}$ using deprived Lifestyle Groups VIII, IX, and X, as an indicator for prioritisation, and Lifestyle Groups I and II as an indicator of the need to critically examine appropriateness, should result in more equitable service provision.

Finally, revascularisation rates in some districts are low compared with others in the region, and in view of the British Cardiac Society's $^{39}$ recommendation of $1000 /$ million revascularisation procedures per annum. Consideration needs to be given to increasing the total rate, with any increase targeted at the socioeconomically deprived, after consideration of appropriateness criteria.

We thank David Bensley and David Merrick of the Public Health Directorate Analysis Unit, and John Reed of the Information Department of the former Yorkshire Regional Health Authority, for advice and data. We also thank Professor Bob Haward, forme Director of Public Health for YRHA for permission to use material from the 1994 annual report; and Professor Rhys Williams of the Nuffield Institute for Health for his comments.

Funding: South Humber Health Authority.

Conflicts of interest: none.

1 Curtis S, Eames M, Ben-Shlomo Y, et al. Geographical differences in CHD mortality in England: implications for local health planning. Health Education fournal 1993;52:72-8.

2 Stringfellow C. Ischaemic heart disease. Poor man's disease in rich man's society. Interim Report No 2. Hospital admission data. Brigg: United Health, 1994.

3 Payne N, Saul C. Variations in use of cardiology services in a health authority: comparison of coronary artery revascularisation rates with prevalence of angina and coronary mortality. BMf 1997;314:257-61.

4 Bryce C, Curtis S, Mohan J. Coronary heart disease: trends in spatial inequalities and implications for health. Soc Sci in spatial inequalities

5 Report by the Variations Sub-Group of the CMO's Health of the Nation Working Group. Variations in health: what can the Department of Health and the NHS do? London: $\mathrm{DOH}$ 1995.
6 Department of Health. Health of the Nation. White Paper. London: HMSO, 1992

7 Macintyre S. The role of health services in relation to nequalities in health in Europe. In: Fox J, ed. Health nequalities in European countries. European Science Foundation. Aldershot: Gower, 317-32.

8 Mooney GH. Equity in health care: confronting the confusion. HERU Discussion Paper no. 11/82. Health Economics Research Unit. Aberdeen: University of Aberdeen, 1982.

9 Epstein AM, Stern RS, Weissman JS. Do the poor cost more? A multihospital study of patients' socioeconomic status and use of hospital resources. $N$ Engl f $\mathrm{Med}$ 1990;322:1122-8.

10 Audit Commission. Dear to our hearts: commissioning services for the treatment and prevention of coronary heart disease. for the treatment and preve
London: HMSO, 1995.

11 Yusef S, Zucker D, Peduzzi I, et al. Effective coronary bypass graft surgery and survival: Overview of 10 year results from graft surgery and survival: Overview of 10 year results from Trialist Collaboration. Lancet 1994;344:536-70.

12 Meier B, Gruentzig AR, Siegenthaler WE, et al. Long-term exercise performance after percutaneous transluminal coronary angioplasty and coronary artery bypass grafting. Circulation 1993;68:796-802.

13 Hubner PJB on behalf of the British Cardiac Intervention Society. Cardiac Interventional Procedures in the UK during 1990. Br Heart f 1992;68:434-6.

14 Royal College of Physicians of London and Royal College of Surgeons of England. Provision of services for the diagnosis and treatment of heart disease. Fourth report of the Joint Cardiology Committee. Br Heart f 1991;67:106-16.

15 Clinical Standards Advisory Group. Coronary artery bypass grafting and coronary angioplasty. London: HMSO,1993.

16 Ben-Shlomo Y, Chaturvedi N. Assessing equity in access to health care provision in the UK: does where you live affect your chance of getting a coronary artery bypass graft? $f$ Epidemiol Community Health 1995:49:200-4.

17 Kee F, Gaffney B, Currie S, O'Reilly D. Access to coronary catheterisation: fair shares for all? BMF 1993;307:1305-7.

8 Findlay IN, Dargie HK, Dyke T. Coronary angiography in Glasgow: relation to coronary artery disease and social class. Br Heart $\mathcal{F}$ 1991;66:70.

19 Black N, Langham S, Pettigrew M. Coronary revascularisation: why do rates vary geographically in the UK? F Epidemiol Community Health 1995;49:408-12.

20 CDMS Super Profiles 91. Crosby, Liverpool: CDMS Marketing Services, 1994.

21 Manson-Siddle CJ. Socioeconomic variations in cardiac investigation and revascularisation rates in the (former) Yorkshire tigation and revascularisation rates in the (former) Yorkshire
Region and its constituent districts. Brigg: South Humber Hegion and its constituent

22 Robinson WS. Ecological correlations and the behaviour of individuals. American Sociological Review 1950;15:351-7.

23 Morganstern $\mathrm{H}$. Uses of ecologic analysis in epidemiologic research. Am f Public Health 1982:72:1336-44.

24 Kreiger N. Overcoming the absence of socioeconomic data in medical records: validation and application of censusbased methodology. Am $\mathcal{F}$ Public Health 1992:82:703-10.

25 MacRae K. Socioeconomic deprivation in Britain: Commentaries. Socioeconomic deprivation and health and the economic fallacy. BMF 1994;309:478-9.

26 Sloggett A, Joshi H. Higher mortality in deprived areas: community or personal disadvantage? BMF 1994:309: 1470-4.

27 Hyndman JCG, Holman CDJ, Hockey RL, et al. Misclassification of social disadvantage based on geographical areas: comparison of postcode collec
Epidemiol $1995 ; 24: 165-76$.

28 Carr-Hill R, Rice N. Is enumeration district level an improvement on ward level analysis in studies of deprivation and health? $\mathcal{F}$ Epidemiol Community Health 1995;49 (suppl 2):S28-9.

29 Folwell K. Single measures of deprivation. F Epidemiol Community Health 1995;49 (suppl 2):S51-6.

30 Brown PJB, Hirschfield A, Batey PWJ. Applications of geodemographic methods in the analysis of health condition incidence data. The fournal of the RSAI 1991;70:329-44.

31 Reading F, Openshaw S, Jarvis SN. Measuring child health inequalities using aggregations of Enumeration Districts. fournal of Public Health Medicine 1990;12:160-7.

32 Yorkshire Health. Public Health Report 1994 (Statistical Review). A census based view of the population and its health. Harrogate: 1994.

33 Reading F, Openshaw S, Jarvis S. Are multidimensional social classifications of areas useful in UK health service research? F Epidemiol Community Health 1994;48:192-200.

34 Hart JT. The inverse care law. Lancet 1971;i:405-12.

35 Kee F, Gaffney B, Canavan C, et al. Is choice of general practitioner important for patients having coronary investigations? Quality in Health Care 1994;3:17-22.

36 Chassin MR, Kosecoff J, Park RE, et al. Does inappropriate use explain geographic variations in the use of health care services? $7 A M A 1987 ; 258: 2533-7$.

37 Leape LL, Park RE, Soloman DH, et al. Does inappropriate use explain small-area variations in the use of health care services? $7 A M A$ 1990;263:669-72.

38 Lee P, Murie A. Deprivation indices: targeting areas for policy. A One Day Seminar Paper. Birmingham: Centre for Urban and Regional Studies (CURS) University of Birmingham, 1996.

39 British Cardiac Society. Council statement on the demand and need for cardiac services and the development of a waiting list strategy for cardiac disease. London: 1994:2. 